\title{
The impact on the landscape, environment and society of new productive chains in a mountain area: strategies, analysis and future perspectives
}

\author{
Simona Rainis, ${ }^{1}$ Franco Sulli, ${ }^{2}$ Sirio Rossano Secondo Cividino, ${ }^{3}$ Eliana Cossio ${ }^{4}$ \\ ${ }^{1}$ CirMont (Centro Internazionale di Ricerca per la Montagna), Amaro, Udine; ${ }^{2}$ Mountain Comunity \\ of Carnia Area, Tolmezzo, Udine; ${ }^{3}$ Agricultural and Environmental Sciences, Faculty of \\ Agricolture, University of Udine; ${ }^{4}$ Food Science Department, Faculty of Agricolture, University of \\ Udine, Italy
}

\begin{abstract}
Zootechnical farms enhance the preservation and valorization of the environmental value of the surroundings in marginal areas, such as the mountains of Friuli Venezia Giulia. An important tool for relaunching mountain animal husbandry can be the promotion of an appropriate policy to maintain and develop local food chains, supporting typical products, tightly related to the peculiarity of the agro-ecosystem. The aim of the chain Carne della Montagna Friulana-Carne di Qualità is to create a cooperation among primary producers, transformation companies, sellers and research institutes, in order to develop innovative pathways throughout the production of meat in Carnia (UD). The project was designed in 2007/08 but it was operative from 2010, with a first batch of animals. The stakeholders subscribed a chain agreement, adopting production guidelines and a commercial trademark. Since the meat is not yet ready, the present paper is, in part, an analysis of the preliminary modification of the operative context and, in part, a previsional examination of the possible effect of the activation of this production chain on the area. The results investigated economic, social, landscape, technical and technological (related to food safety) elements. It can be observed, by an introductive evaluation, that this productive circuit may valorize the resources of this mountain area and can enhance zootechnics in mountain areas. The guidelines allow a vertical integration throughout the production path, coordinating all the operators. This type of production can be considered a niche product, related to the territory, with the maximum guarantee for the consumers. The environmental worthiness is the recovering and the improving of these marginal, agricultural areas. Actually, an overall
\end{abstract}

Correspondence: Simona Rainis, CirMont, via J. Linussio 1, 33020 Amaro, Udine, Italy. Te//Fax: +39.0433467124. E-mail: s.rainis@libero.it

Key words: agro-food chains, marginal areas, sustainable development.

Received for publication: 7 May 2010.

Accepted for publication: 13 January 2012.

(C) Copyright S. Rainis et al., 2012

Licensee PAGEPress, Italy

Journal of Agricultural Engineering 2012; XLIII:e2

doi:10.4081/jae.2012.e2

This article is distributed under the terms of the Creative Commons Attribution Noncommercial License (by-nc 3.0) which permits any noncommercial use, distribution, and reproduction in any medium, provided the original author(s) and source are credited. evaluation can be done only from the summer of 2011, when data such as the organoleptic and qualitative characteristics, selling prices, level of appreciation by the customers and landscape effects will be available.

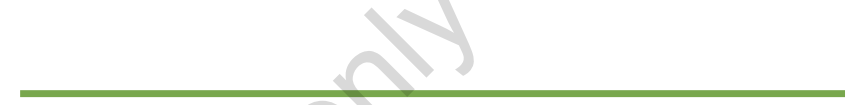

\section{Introduction}

The depopulation of mountain areas and the crisis of the zootechnical compartment, which characterized these last decades (Atlante Statistico della Montagna Italiana, 2007), substantially modified the agricultural and environmental context, determining the progressive deterioration of the landscape. The present situation underlines the necessity to develop strategies for a sustainable growth of these marginal areas (PSR, 2007). In the mountain areas, the presence of stock farms contributes to protect and valorize the landscaped esthetic, the environmental and the area's recreational quality (European Commission, 2002a). Agricultural politics have to enhance the model of a traditional agriculture. This approach allows a more responsible management of the resources, from the ecological and territorial point of view, a very high quality agro-food production, using renewable raw materials and, it guarantees the biodiversity and the autochthon genetics resources (European Commission, 2002b). Furthermore, it is necessary to support and stimulate the development of production-distribution and consumption of local agro-food chains, due to the importance of promoting typical products tightly related to the territory peculiarity and the agro-eco-system (Traversi, 2009). At present, it is more and more important to strengthen the link between the typicality of the local product and the vocation of the area for the evolution of the agrofood system (Peri, 2004). In this social-economic-territorial context, the technical and practical role of an agro-food chain is to give a concrete opportunity to the agricultural sector in crisis, becoming a multidisciplinary tool for the management in order to protect the zootechnical compartment and to preserve the environmental and rural space. It has been observed that biodiversity in agroecosystems depends on both landscape heterogeneity and farm management; in particular, Weibull and colleagues (2003) identified the farmers as important decision-makers in conservation issues. A recent case study, carried out in the mountains of Altopiano dei Sette Comuni (VI), underlines that, in marginal sites such as in the present paper, the extensive firms confirm their great eco-compatibility and do not turn out disadvantaged in terms of profitability (Cozzi, 2006). The valorization of local genetic resources and extensive production techniques are certainly the challenge which the mountain animal husbandry has to collect and overcome with a winning strategy (Segre, 1997). The aim of the project is to create a cooperation between primary producers, the transformation companies, the commercial partners and the research 
institutes, in order to identify and develop alternative pathways throughout the production chain. Analyzing the different steps of the present chain, it will be possible to identify the impacts of a new production circuit on the technical-landscape-economic and social aspects in a mountain area.

\section{Materials and methods}

\section{Description and management of the project}

The operative area is the Carnia region (the Mountain Community of the Carnia Area), in Friuli Venezia Giulia (Figures 1 and 2). This project is denominated: Carne della Montagna Friulana-Carne di Qualità and its role is to protect and valorize the meat (beef and swine origin) and its transformations produced in Carnia.

The stakeholders (breeders, slaughterhouses, traders and the institutions) subscribed a chain agreement, adopting production guidelines (where a rigid food plan and all the modalities for the transparency and traceability of the production process are clearly specified) and a commercial trademark (Figure 3).

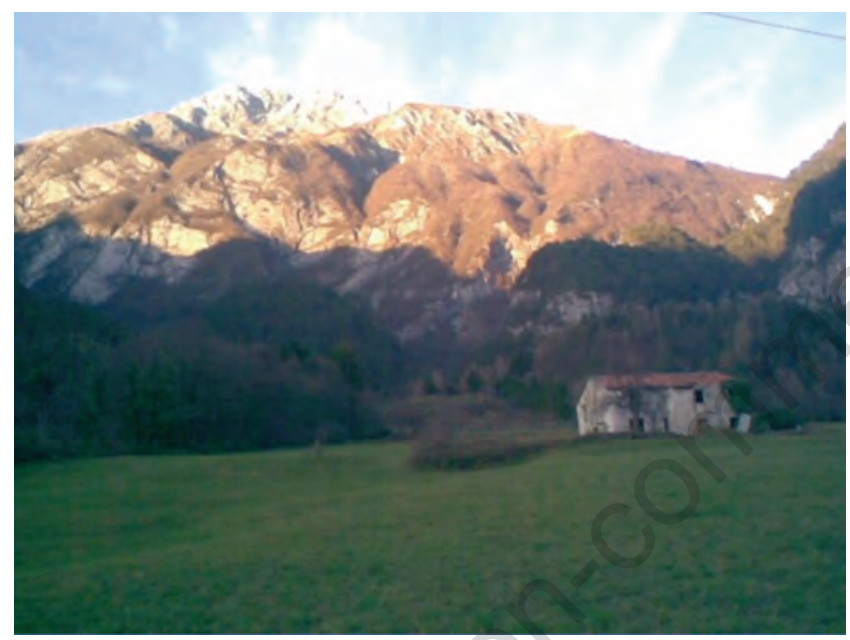

Figure 1. Monte Amariana in Carnia-UD. (Photo by Chiara Bettiga, 2010).

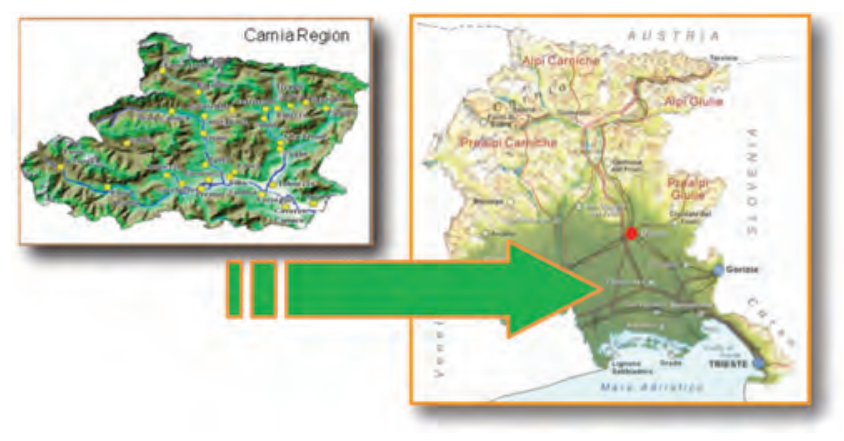

Figure 2. Carnia Region, in Friuli Venezia Giulia.
Two different pathways to produce bovine meat were activated: - cow-calf line, where animals with their calves live free in paddocks or in pasture lands;

- light vitellus husbandry, that is typical of dairy farms.

From the genetic point of view, the project was focused on the valorization of autochthon races such as Pezzata Rossa.

Calf breeding was divided in two different phases in order to rationalize human and economical resources:

- the growth phase (until 8-10 months), to be carried out on the farms in Carnia;

- the finishing phase (until 14-18 months), to be completed on stockfarms specialized in cow breeding for the production of meat (in the Piedmont area).

Animals, as regulated in the guidelines, have to be fed with local forage (at least 50\%), and with a physiological diet which guarantees good quality meat. During the finishing phase, the calves received a ration constituted by raw materials, almost exclusively, produced in this farm. For the porcine meat, a stock farm defined as a Pilot Farm by the UE Commission, for the Pig Genetic Qualification Research Scheme was chosen. The breeding rules, the nutrition and the swine races are the same as specified in the Control System of the DOP Prosciutto di San Daniele, as reported on the Official Journal of the

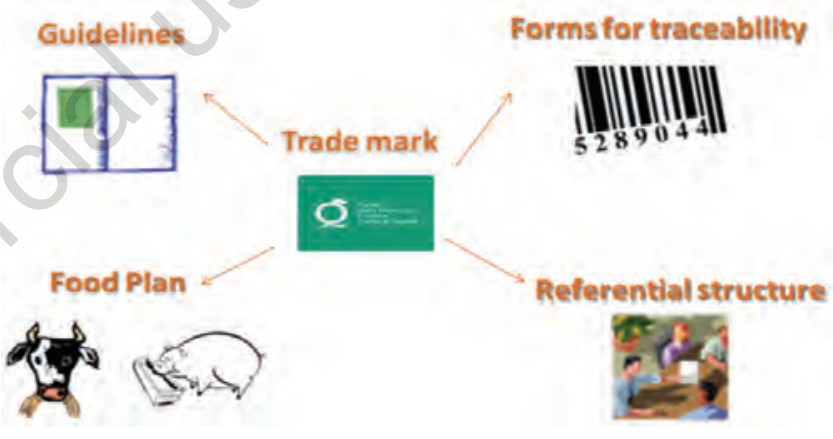

Figure 3. Characteristic elements of the Carne della Montagna Friulana-Carne di Qualità chain.

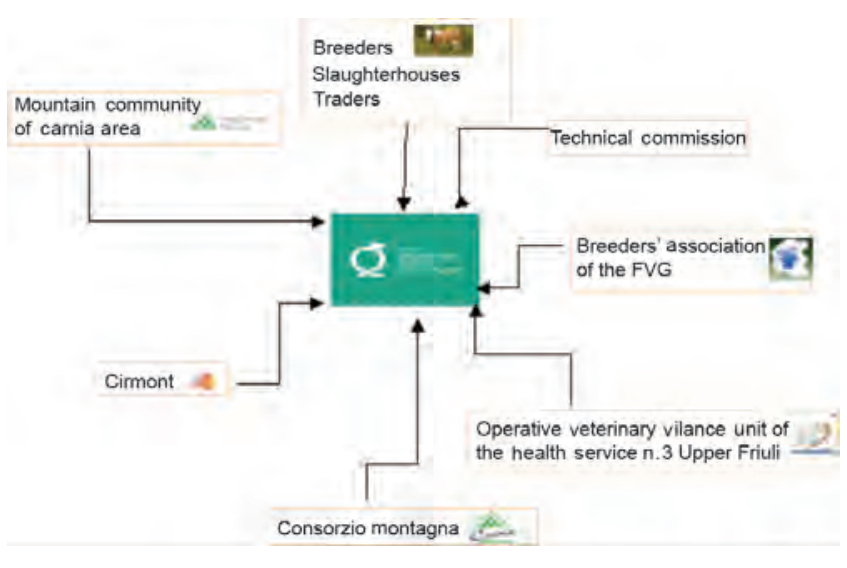

Figure 4. The stakeholders and the institutions that collaborate in the present production chain. 


\begin{tabular}{|c|c|}
\hline Strenghts & Weaknesses \\
\hline $\begin{array}{l}\text { - territorial vocation; } \\
\text { - eco-sustainable zootechnical system; } \\
\text { - good image of autochthon products among the buyers; } \\
\text { - growing interest by the consumers in traditional products, obtained } \\
\text { with eco-sustainable techniques and respecting animal } \\
\text { wellness; } \\
\text { - attention toward the difficulties of marginal areas by the } \\
\text { institutions; } \\
\text { - local grants. }\end{array}$ & $\begin{array}{l}\text { - structural inadequacy (technical deficiencies, small dimensions } \\
\text { and low generational recharge); } \\
\text { - low attitude to collaborate and to develop vertical integration } \\
\text { forms of cooperation of the stakeholders; } \\
\text { - high production costs; } \\
\text { - lack of an efficient system of distribution and sale of the } \\
\text { products; } \\
\text { - morphological and climate difficulties, typical of the alpine } \\
\text { areas; } \\
\text { - lower agrarian production, related to the short productive } \\
\text { season, to mechanization difficulties, to the long distances to } \\
\text { production and service sites. }\end{array}$ \\
\hline Opportunities & Threats \\
\hline $\begin{array}{l}\text { - increasing the competition of the agriculture and forestry sector, } \\
\text { supporting the restructuring, the development and the innovation; } \\
\text { - valorization of the environmental and rural landscape; } \\
\text { throughout a strategic territorial management; } \\
\text { - consolidation of the cultural heritage; } \\
\text { - improving the quality of life in rural areas, promoting } \\
\text { differentiation of the production activities; } \\
\text { - enhancing the strong link between the agro-food sector and } \\
\text { tourism, thanks to the positive image of mountain areas; } \\
\text { - high quality, safe and traceable products. }\end{array}$ & $\begin{array}{l}\text { - progressive reduction of the number of farms in this area; } \\
\text { - depopulation of the territory; } \\
\text { - high production costs of the whole chain; } \\
\text { - competition from other stakeholders. }\end{array}$ \\
\hline
\end{tabular}

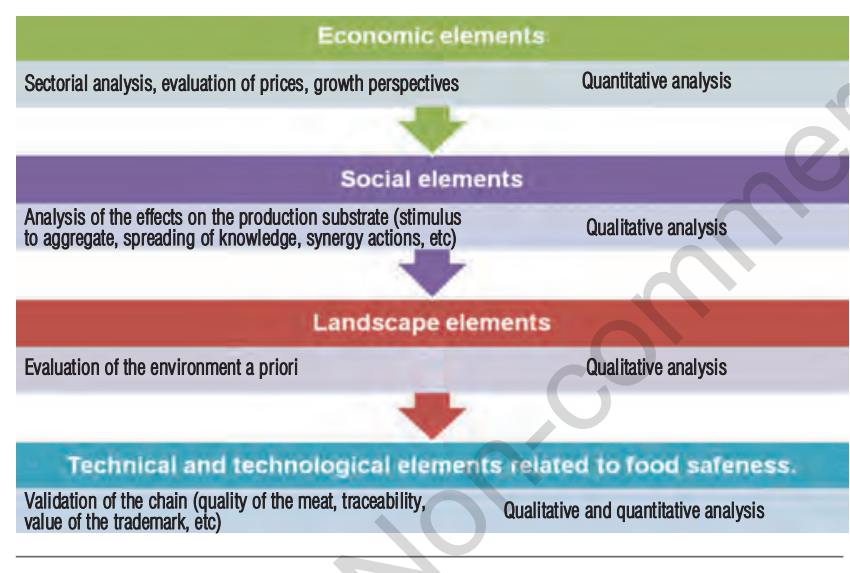

Figure 6. The methodological approach [www.eim.gov.it].

Italian Repubblic (2007). The slaughter and commercialization of the final product is carried out in three private structures. The coordination and control of the present chain, from the bureaucratical and economical point of view, is carried out by the Mountain Community of the Carnia Area (leader of the project), the Cirmont (International Research Center for Mountain) and the Consorzio Montagna. The whole circuit is strictly controlled by the Operative Veterinary Vigilance Unit of the Health Service n. 3 Upper Friuli, in order to guarantee the safety of the meat, from a health point of view. The Breeders' Association of the FVG carries out the functional controls and the technical support (Figure 4).

\section{Contest analysis}

The project was designed in $2007 / 08$, but it became operative in 2010. The first steps were focused on the evaluation of the market sit- uation, the contextual needs and previous experience. The first activities were characterized by some meetings, involving all the stakeholders (breeders, slaughterhouses, traders, research center and local authorities). The output of the consultation phase was a Swot analysis (Dyson, 2004) that produced important indicators from the methodological and administrative point of view, in order to manage this production chain (Figure 5).

\section{Analysis of the effects}

From the methodological point of view (EIM, 2010), the following elements were considered:

Economic elements (Ee) sectorial analysis, price trend evaluations,

future perspectives etc.;

Social elements (Se) effects on the production substrate, in particular the aggregation needs, the spreading of knowledge, synergy, the collaboration among the stakeholders;

Landscape elements (Le) evaluation of the possible new recoverable grazing sites;

Technical and technological elements related to food safety (Te) analysis of meat organoleptic and sensorial characteristics, the traceability of the whole chain, etc..

The comparative criteria choice was based on the interpretation reported below:

- integrate approach (which considers that every action applied on an area has to be analyzed in a complex way, because it affords positive and negative effects on different elements);

- synergic approach (which evaluates all the stakeholders as actors of the same production pathway).

Furthermore, in order to standardize the scientific interpretation, two different evaluation levels were considered:

- quantitative, based on objective data (prices, trends, etc.);

- qualitative, focused on subjective elements (impact, synergies, etc.) (Figure 6). 


\section{Results and discussion}

The first experimental animal batch was introduced in this production pathway in the autumn of 2010 . At the moment they are in the last phase, waiting to reach the weight to be slaughtered. Therefore the present paper is in part an analysis of the operative context modification and, in part, a previsional examination of the possible effects of the Ee, Se, Le and Te by the activation of this production chain.

\section{Economic elements}

The design of this project is an answer to the urgent necessity of the Carnia area to find satisfactory economic solutions and a remunerative integration to their income for zootechnical farms. In particular, part of them have great difficulties related to their lack of the minimum parameters for milk production and they need to modify their product orientation. In order to have the opportunity to survive. The coordination of the meat promotion and marketing, creating a short cut, allows to concentrate the offer and to reduce the production costs. The first commercial transitions (from the mountain breeders to the finishing one) have enabled an increment of the profit margin, with an increase of $5 \%$ of the calves' shelling prices corresponded to the breeders with, respect to the current market. Meat commercialization has not yet been tried, so it is an assumption that it could increment the shelling price, because consumers generally appreciate the mountain products (Leonarduzzi, 2006). In the periodical meetings, organized by the project leader, the stakeholders expressed a particular satisfaction for the marketing transitions. This can be considered a safety net in a protected context, where price volatility is regulated (Barilla Center for Food Nutrition, 2009). Furthermore, an other opportunity for the partners was the Regional Public Funds of the PSR 2007-2013 of FVG, related to the present chain. This offered the possibility to modernize and to bring up to standard the stock farms (in order to reduce the environmental impact and enhance animal welfare) and to potentiate the slaughterhouse industry. The growth perspectives of this commercial pathway are based on the cooperation among the role players of the chain, who can stimulate the production increment and the new processes and product creation. The governance strategies and the spread action of the chain in the agriculture system help to valorize the role of the small and medium sized firm (as a stock farm or a private slaughterhouse); as a matter of fact, the aggregation in a system encourages the economical sustainability of the production reality, the virtuous synergies and the scale economies. These actions positively influence the increased income perceived by the stakeholders. This kind of production organization promotes and gives visibility to the farms, therefore, the fundamental role in the local economy of the breeder is recognized (Milano, 2006).

\section{Social elements}

One of the most important results obtained by the activation of the present production was certainly the creation of cooperation among the stakeholders, with the subscription of the chain agreement. In a very disintegrated reality, such as the mountains of Friuli Venezia Giulia, this was a very significant target to be scored. Another appreciable goal of the project was the ability to stimulate a commercial dialog between the mountain territory and the Piedmont one, where both the finishing bovine farm and the pig farms are found. This is a little step to create a new way of thinking, traditionally hugely closed, towards new trade horizons and outlets. Creating the system, starting interactions among primary producers, agro-industries, distribution and assisting knowledge transmission, are the only ways to individualize and develop innovative pathways throughout the chain (Raffaelli, 2005). The institutions' participation in the project guarantees a qual- ified and technical contribution. The transactors always have a reference to compare with, in order to solve different possible problems related to the production process. In particular, in Carnia, a fundamental goal to be achieved is to overcome the mutual mistrust among the stakeholders, which has always affected the whole area. In particular, the aim of the whole project is also to create a development perspective, valorizing and retraining the traditional local products (Archdiocese of Udine, 2001).

\section{Landscape elements}

A significant evaluation of the impact on landscape can be scientifically and objectively carried out after some years from beginning of the production chain, so for this reason, at the moment, only a projective analysis can be achieved. The gradual and inexorable abandonment of the fields, pastures and woods and their structure modification are strictly related to the farms closing in the mountain areas (PSR 20072013 of Autonomous Region of FVG) All the activities connected with animal husbandry, such as mowing, grazing in marginal areas, river flood control, path accommodation, wood utilization, are fundamental for a rational management of the territory (Mattana, 2003). In particular, as ruled in the present project guidelines, farmers have to feed the calves with forage coming, almost $50 \%$, from the Carnia area. This is a stimulus to recover abandoned pasture-lands (Figure 7).

The relaunching of animal husbandry in mountain areas, stimulated also by this production chain, has, certainly, positive effects on the
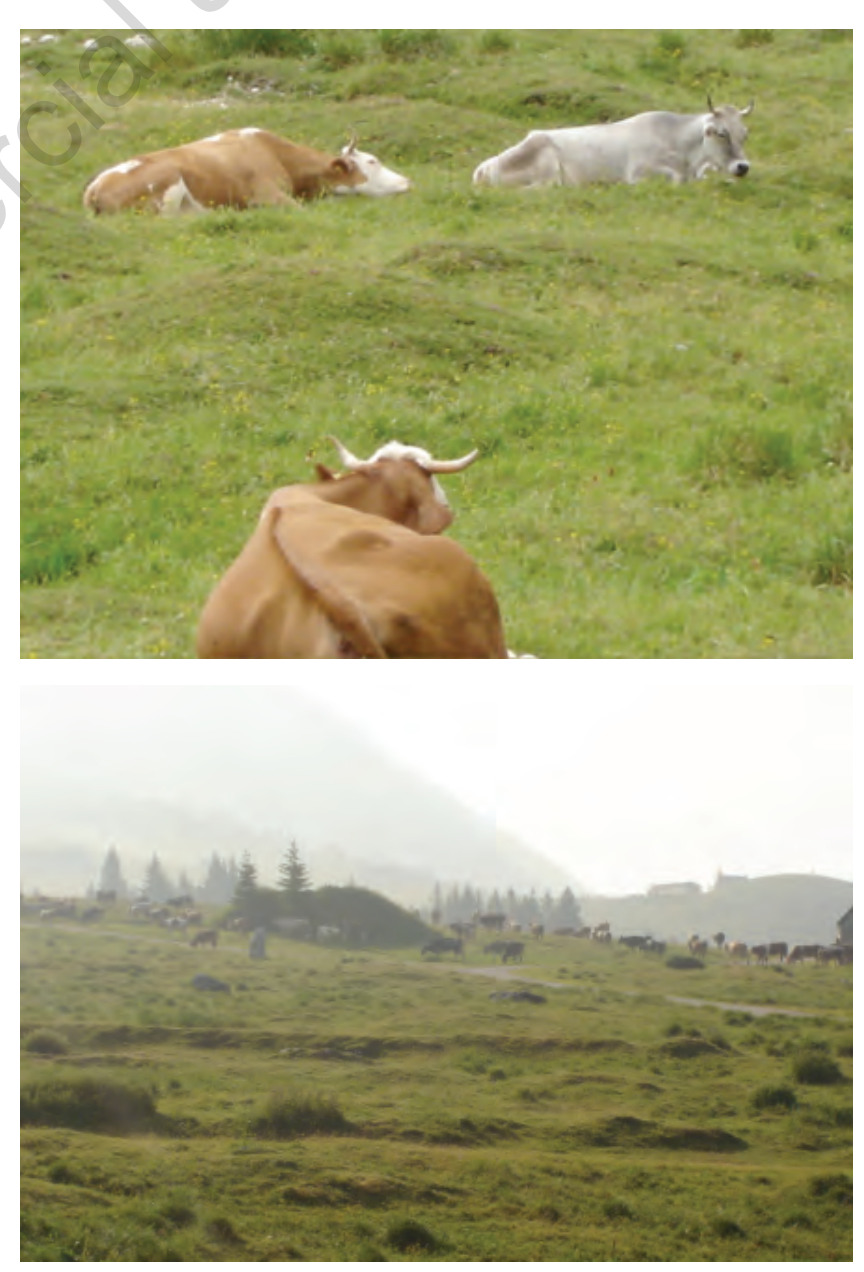

Figure 7. Grazing animals in the Alps. (Photo by Simona Rainis, 2010). 
environment and, in particular, its contributions can be listed as follows (Rainis, 2008):

- to offer an opportunity to old breeders and to cattlemen with particular problems, for structural unsuitability of their farms, in producing milk. This production chain, involving a significant group of farmers $(n=16)$, gives them an opportunity to continue with their activity, otherwise destined to close;

- to valorize genetic resources and to safeguard native races (biodiversity protection). Local breeds have been reduced in the last decades in the Friuli Venezia Giulia Region and, in particular, in hilly and mountain areas, as well as the number of small-medium farms. Nowadays, high input livestock systems and production technique standardizations are criticized, while traditional systems and autochthonous breeds are re-evaluated (Loszach, 2008). This project contributes to maintain or improve existing populations and increase genetic variability;

- to exploit traditional local production techniques, exalting the binomial typical product-territory, which correlates merchandize and organoleptic characteristics of the local agro-system with respect to the production area;

- to stimulate gastronomic-rural tourism and new trade relationships (Battaglini, 2004);

- the identification of new strategies for the traditional products of mountain area valorization is an important tool for a sustainable development of marginal regions (Elias, 2010).

\section{Technical and technological elements related to food safety}

The meat of Carne della Montagna Friulana-Carne di Qualità is a certified and traceable product. All the pathway was studied to enhance and to encourage traceability, in particular the forms filled in by all the operators, step by step, and the transparency in the relationship among the partners. In the future, it will be possible to organize tours for the customers in the stock farms, to give them the opportunity to visit and appreciate personally the production reality where the animals live. The whole features of this production chain increases the perception of the final product's added value, as indicated in a case investigated by Milano (2006).

A high quality husbandry system, for the bovine and swine meat production, can contribute to enhance the animal's welfare and consequently the final product organoleptic and sensorial characteristics, as reported in previous studies on Blonde d'Aquitaine bovines (Cozzi, 2001) in similar conditions. This is important for customer safety: they feel protected by the dangerous emergencies of the food industries, such as BSE, bird and swine flu, etc.. The buyers increasingly require, a high and competitive quality standard, which is unequivocally related to the typicality of the traditional products and guaranteed by the trademark (Peri, 2004). The organoleptic characteristics analysis of the present product will be evaluated as soon as the meat will be available (indicatively in the summer of 2011). The same time can be required for the real customer appreciation level detection, meaning when the meat reaches the shops.

\section{Conclusions}

The chain Carne della Montagna-Carne di Qualità was created on the basis of a specific stakeholder's will, in order to start a program able to valorize first of all the mountain environment and its highly valued resources. The fundamental aim is to re-evalutate a low exploited territory with its typical goods (Zanetti, 2007). The present project is char-

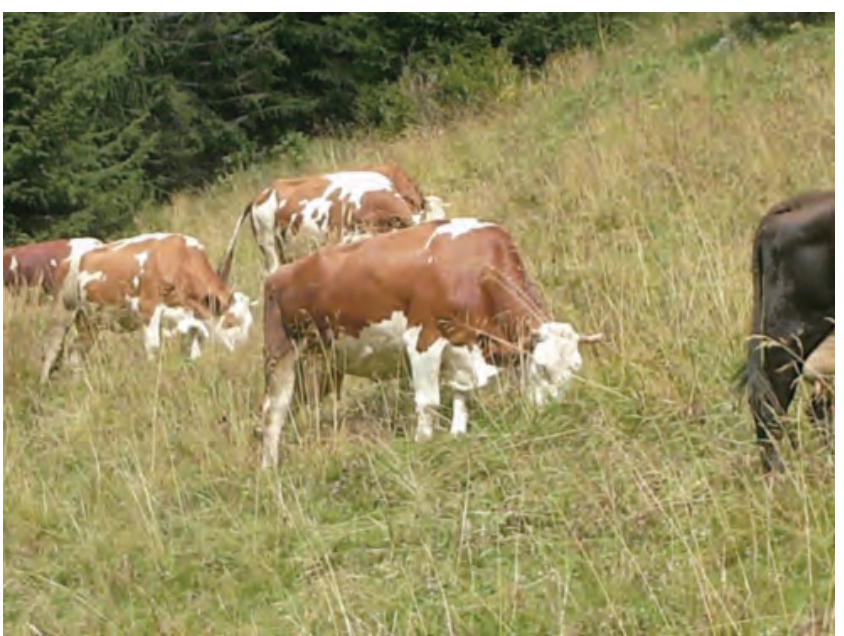

Figures 8. Cows grazing in pastures that are difficult to be mowed. (Photo by Mattia Prunas, 2010).

acterized by an approach starting from the bottom, which involves the production substrate (Atlante Statistico della Montagna Italiana, 2007). The adopted guidelines represents a practical vertical integration: it correlates stock farms, slaughterhouses and shops. Actually the project can be considered innovative in Friuli Venezia Giulia, because the predominant animal husbandry production attitude in the mountain region is addressed to milk production. Otherwise it can be interpreted as a qualifying element, because the breeding of the cows is brought out in a very low anthropic concentration area, with animals free to graze in the Alps, best quality food given and high welfare parameters for cattle respected. The chain can be defined as a niche, far from large markets and with an exclusive type of product. This meat is closely connected to the environmental typology, where it is produced and transformed, and it offers maximum guarantees of traceability to the final consumer (chain certification). The buyers can purchase food protected by sanitary emergencies and obtained from a non aggressive and extensive agriculture (Farina, 2009).The project also contributes to relaunch mountain zootechnics. This aspect is very important because it helps some breeders to continue their activity. The ecological value of the present production organization is certainl improvement in the territory and the recovery of discarded pastures. In fact, it gives a concrete answer to the huge necessity to mow and settle down large grasses, because cows with their calves can graze in step areas and farmers are motivated to mow abandoned areas to produce winter season forage (Figure 8). In this way, the landscape is concretely settled down, recovered and valorized. Actually, some conclusions can be observed only from the summer of 2011 , when the meat will be ready to be commercialized and analyzed. With these kinds of data (organoleptic and qualitative characteristics, selling prices, appreciation level by the customers and landscape effects) it will be possible to evaluate the overall effects of this production chain.

\section{References}

Archdiocese of Udine, 2001. Vivere in montagna si può. Atti del convegno diocesano sui problemi della montagna. Archdiocese of Udine, Vicariate for Culture, Udine, Italy. 
Atlante Statistico della Montagna Italiana, 2007. Istituto Nazionale di Statistica e Istituto Nazionale della Montagna, Roma, Italy.

Barilla Center for Food Nutrition, 2009. Sfide della food security. Parma, Italy.

Battaglini L, Mimosi A, Ighina A, Lussiana C, Malfatto V, Bianchi M, 2004. Sistemi zootecnici alpini e produzioni legate al territorio. Il sistema delle malghe alpine. Aspetti agro-zootecnici, paesaggistici e turistici. Quaderni SoZooAlp. 1:42-52.

Cozzi G, Preciso SF, Gottardo F, Andrighetto F, Andrighetto I, 2001. L'allevamento biologico come alternativa ai sistemi intensivi di produzione della carne bovina. L'Informatore Agrario 57:101-107.

Cozzi G, Bizzotto M, Rigoni Stern G, 2006. Uso del territorio, impatto ambientale, benessere degli animali e sostenibilità economica dei sistemi di allevamento della vacca da latte presenti in montagna. il caso di studio dell'altopiano di asiago. Quaderni SoZooAlp. 3:7-25.

Dyson RG, 2004. Strategic development and SWOT analysis at the University of Warwick. Eur. J. Oper. Res. 152:631-640.

EIM, 2010. Approccio trasversale e multidisciplinare per lo studio dei territori montani. Available from: http:www.eim.gov.it

Elias G, 2010. Prodotti agroalimentari tradizionali della montagna italiana. Tradizione e innovazione in cinque casi studio. FrancoAngeli, Milano, Italy.

European Commission, 2002a. Marketing Sustainable Agriculture: an analysis of the potential role of new food supply chains in sustainable rural development. The 5th Framework Programme 1998-2002, Brussels, Belgium.

European Commission, 2002b. Strategies of the European Commission for a sustainable development. Brussels, Belgium.

Farina R, Pagliarino E, 2009. Una montagna da mangiare: prodotti tipici della montagna italiana fra tradizione e innovazione. SLM, Sopra il Livello del Mare. 35:42-49.

Italian Regulation, 2007. Official Journal n. 77, 2/04/2007.

Leonarduzzi C, 2006. Prodotti tradizionali della montagna friulana: identificazione, produzione e prospettive economiche. Degree Diss., Università degli Studi di Udine, Italy.
Loszach S, Bianco E, Bovolenta S, 2008. Biodiversity and mountain livestock in Friuli Venezia Giulia Region. Quaderni SoZooAlp. 5:278285 .

Mattana U, Vardanega E, 2003. Montagne, dimore, segni dell'uomo. Rapporti in trasformazione. Atti della $2^{\circ}$ giornata di studio sulle "terre alte". Università di Padova, Italy.

Milano S. Ponzio R, 2006. Report Presìdi. Slow food. 2:146-160.

Peri C, Lavelli V, Marjani A, Qualità nelle aziende e nelle filiere agroalimentari. Gestione e certificazione dei sistemi per la qualità, per la rintracciabilità e per l'igiene. Biblioteca Tecnica Hoepli, 2004, Milano.

PSR, 2007. Piano di Sviluppo Rurale 2007-2013 della Regione Autonoma Friuli Venezia Giulia, Trieste, Italy.

Raffaelli R, 2005. Sostenibilità e multifunzionalità dell'agricoltura di montagna. Istituto Nazionale della Montagna, Bologna, Italy.

Rainis S, 2008. Indagine di mercato sulle filiere produttive agroalimentari collegate alla valorizzazione del prodotto carne presenti e potenzialmente attivabili nella Comunità Montana della Carnia. Comunità Montana della Carnia, Tolmezzo (UD), Italy.

Segre L, 1997. La montagna, una politica possibile. Atti della "giornata di studio". Università degli Studi di Milano, Consiglio Regionale della Lombardia, Associazione ex consiglieri regionali della Lombardia, Milano, Italy.

Traversi F, 2009. La qualità come leva per la competitività euro mediterranea delle montagne italiane. SLM, Sopra il Livello del Mare. 35:50-54.

Weibull A-C, Östman 0, Granqvist A, 2003. Species richness in agroecosystems: the effect of landscape, habitat and farm management. Biodiversity and Conservation 12:1335-1355.

Zanetti A, Malerba A, 2007. XIII relazione sullo stato della montagna italiana. Comitato Tecnico Interministeriale per la Montagna, Presidenza del Consiglio dei Ministri, Dipartimento per la Programmazione ed il Coordinamento della Politica Economica, Roma, Italy. 